\title{
The Visible: Element of the Social
}

\author{
Andrea Mubi Brighenti* \\ Social and Urban Theory, Department of Sociology and Social Research, University of Trento, Trento, Italy
}

In the context of a social-theoretical take on the link between social life and visibility, this paper invites to shift the focus from visibility phenomena to "the visible". A theory of visibility, it is submitted, must be constructed as a theory of the medium. In opposition to visibility as a set of formal relations, what the visible brings to the fore is the existence of a mid-term, a connective tissue. Also, if a theory is a prelude to a science, then a theory is needed that makes possible to measure the visible in itself. The development of an "intrinsic" theory of the visible, one capable of generating its own variables and constants, along with the conceptual space for their articulation, is retrieved through the joint contributions of surface theories (Simmel, Goffman, Portmann) and intensity theories (Deleuze, Thom). The piece presents a set of notions that could be of use to analyze the fiber of the visible and the trajectories occurring in the visible, in view of laying out a series of laws of the visible.

\section{OPEN ACCESS}

Edited by:

Maurizio Meloni,

University of Sheffield,

United Kingdom

Reviewed by:

Sebastiano Citroni, University of Milano-Bicocca,

Yi-Tung Ohat Italy National Pingtung University,

Taiwan

${ }^{*}$ Correspondence:

Andrea Mubi Brighenti andrea.brighenti@unitn.it

Specialty section: This article was submitted to Sociological Theory, a section of the journal

Frontiers in Sociology

Received: 16 June 2017 Accepted: 17 October 2017 Published: 06 November 2017

Citation:

Brighenti AM (2017) The Visible: Element of the Social.

Front. Sociol. 2:17. doi: 10.3389/fsoc.2017.00017
Keywords: social theory, social life, visibility, the visible, saliences/pregnances, regime of the infinitesimal, elemental analysis

\section{INTRODUCTION: FROM VISIBILITY TO THE VISIBLE}

In a previous work, the idea has been advanced that visibility can be regarded as a social-scientific category (Brighenti, 2007, 2010a). Its relevance, it was suggested, is both historical (related as it is to the significance that the management of inter-visibilities has acquired in contemporary society) and analytical (in that the notion itself seems to call for a theory that is not yet present in the market of existing social theories). Also, a previous attempt has been made to articulate the distinction between visibility and visuality (Brighenti, 2008). Rather than simply a sensory register-which is evident in social interaction analysis-visibility concerns an enlarged domain that gathers together and interweaves the sensory and the representational (or, symbolic) registers. It is a complex terrain where a continuum between what can be seen and what can be said is laid out. This is also why the attempt to develop a theory to capture a series of "laws of visibility" requires caution. As has been argued, all social theory is, in a sense, a "way of seeing," or even properly "visual work" (Woodiwiss, 2005). For Deleuze (Deleuze and Foucault, 1972), however, theory is also and above all wall-piercing-not only scoping reality, but already acting upon it ("representation is no longer, there is only action"). Clearly, ways of thinking about social life affect it directly-as once Frazer (1994 [1890]), p. 181, put it, long before William I. Thomas, "imagination acts upon man as really as does gravitation, and may kill him as certainly as a dose of prussic acid." Theory is an integral part of life, it is an expression of life itself, which evolves by theorizing no less than by acting. Theory is an ongoing natural production.

All attempts to theorize visibility should thus be oriented toward an integral conception capable of dealing with the complexity deriving from the praxeology of theory as well as the specific nature of its object-these two components being distinguishable only in a very coarse and approximate

${ }^{1}$ John Levi Martin has aptly reminded me that Kant's conception of imagination in his Third Critique, from 1790, already announces and heralds this fact. 
way. A theory of visibility appears as a relational theory. In twentieth century social theory, two most noticeable relational theories include for instance system theory and field theory [on the former, see Luhmann (2012); on the latter, see Martin (2003)]. Can visibility be effectively tackled through a systemic or fieldtheoretical apparatus? This text stems from a similar question. What is proposed here is a comparison between a few key socialtheoretical notions, pointing toward a potential renewal of social theory for the twenty-first century. In order to advance toward an answer to the research question just outlined, a proposal is made to shift the focus of enquiry from visibility to the visible. While the distinction may at first look negligible, the proposal hints to the idea that a theory of visibility must be constructed as a theory of the medium. ${ }^{2}$ In opposition to visibility as a set of formal relations, what "the visible" brings to the fore is the existence of a mid-term, a connective tissue, an "air that bathes the globe"-along with the insight that such a peculiar atmosphere constitutes the quale and the proprium of social life. Consequently, the move from visibility to the visible is understood here as implying that systemic, structuralist, and structural-genetic explanations are helpful, but only partially sufficient for a more advanced social theory of visibility.

Obviously, social life contains processes and facts that remain practically unseen or unperceived from the local perspectives of the involved actors. Hence, it does not coincide with what is seen: it does not coincide with attention-a corollary of Durkheim's and Mauss' thesis that social life remains distinct from the life of the associated members. Despite that, it is not wrong to assume that the social entertains a special liaison with visibility-as will be detailed below, it may be even said to be written in the visible. ${ }^{3}$ Now, the visible is not the seen, just as the invisible is not the unseen. Inside the visible, the partition between the seen and the unseen, the noticed and the unnoticed can be accomplished. For its part, the visible is beyond the seen and the unseen, beyond attention and interest; if ever, attentive phenomena are tropisms and vectors inside the visible. Because the seen and the unseen entirely occupy the visible, something cannot be seen and unseen at the same time. On the other hand, the relation between the visible and the invisible is more subtle and should not be confused with the previous one. The latter is, in fact, not a relation of opposition and mutual exclusion. On the contrary, the invisible constantly contributes to the visible, it adds to it. In this sense, the invisible is no less operative than the visible. The invisible is the visible without a theme. This is why, as will be articulated below, visibility itself can only be understood as a notion of virtuality, not actuality. The visible represents a virtual expanse, where the virtual appears in the first place as a "mist" of images surrounding each actual object (Deleuze, 1996).

The question then is: is there any hierarchy between the virtual and the actual, so that one of these two dimensions could be said to be more "real" than the other? In a famous letter to Michel

\footnotetext{
${ }^{2}$ In sociology, medium theory is usually associated with Marshall McLuhan (1994 [1964]). For his part, Debray (1991) has developed a whole discipline of mediology. In the 1950s, Canguilhem (2015 [1951]) had already reconstructed the birth of notion of medium in modern biology.

${ }^{3}$ For instance, the whole oeuvre of Michel Foucault appears to be premised upon a similar assumption.
}

Foucault, the painter René Magritte (1966) for instance asks: why do we stick to the prejudice according to which the visible can hide the invisible, but the invisible cannot hide anything? Raising such a question, which may sound provocative but is effectively heuristic, what Magritte is allusively pointing at is the fact that a hierarchical theory of the visible-one that would structure the domain of the visible into a stable arrangement in which certain elements or regions would stand "above" others and in reciprocal contrast-is always certainly possible, but inevitably arbitrary. ${ }^{4}$ Hierarchical theories are axiological; it means that a whole morality is introduced by them that prevents a naturalistic and thus also a scientific approach to the visible. One may baffled by the idea that the painter of The Empire of Light and The Treachery of Images was a supporter of naturalism, but this is precisely what Magritte demanded from theory-namely, thinking the visible and the invisible immanently, from within.

If a theory is a prelude to a science, then we need a theory that also makes possible to measure the visible. How is it possible to measure the visible in se et per se? Before the issue of laying out the laws of the visible, what the question of measure draws our attention to is the search for workable alternatives to think the visible in ways that do not surreptitiously introduce external, arbitrary criteria, codes, and hierarchies. How to develop an intrinsic theory of the visible, one capable of generating its own variables and constants, along with the conceptual space for their articulation? The social theorists of surfaces, from Simmel to Goffman, have attempted to do this. The surface offers indeed a possibility to theorize the visible from within. These authors have not ceased to remind us that the apparent is social life itself, nothing more and nothing less. In this light, social life is coterminous with presence, luminosity, visibility-a surface effect. The mystery of surfaces, the depth of appearances, these authors have stressed, is intrinsic, not due to extrinsic hierarchies superimposed at some point onto the visible. Merleau-Ponty (1966), p. 186, observed to this effect that "what is proper of the visible is the fact of being a surface of endless depth": depth is not beneath the surface, but inside it. An earlier author of surfaceality in social life is certainly Tarde. For him, social reality is appearance tout court. Moral acts, for instance, are only and exclusively visible acts - there is no hidden morality (Tarde, 1886). ${ }^{5}$ If, in the "pure sociology" of Tarde,

\footnotetext{
${ }^{4}$ Magritte stresses the existence of an actual "mystery" in the relationship between the visible and the invisible, and also refers to a distinction between a level of facts (de facto) and a level of rights (de iure)-the latter corresponds to what we call virtuality: "Since some time, there is a curious tendency to attribute primacy to 'the invisible.' It's the fault of a confused literature, whose interest evaporates if we just admit that the visible can be hidden but the invisible does not hide anything: it can be known or ignored, nothing more. It makes no sense to give primacy to the invisible over the visible, nor, for that matter, the other way around. What does not 'lack' importance is the mystery factually evoked by the visible and the invisible, a mystery, which can be rightfully evoked by the thought that unites 'the things' in the order evoking the mystery." (my translation).

${ }^{5}$ See in particular the following passage: "From the individual point of view, immorality is essentially the rupture of a moral habit-rupture which is the source of an immoral habit. Until the moral habit resists, with or without temptations, there is morality. One could object: it's a simply apparent morality. Yes, but by appearing it is seen, and serves as an example. When on the contrary it is immorality that appears, it spreads by imitative rays in its environment, and that is the moment when it begins its social existence. Indeed, social reality is, par excellence,
} 
imitation embodies the moving force of social life (not a form in itself, but rather a transfer of forms), visibility can be identified as the condition that specifies the imitative relation. Although imitation is not, in itself, a visible form, no imitation would be possible without a space of inter-visibility where inter-psychic encounters are located. In a different context, Simmel (1908), SIX ex. II, located the most fundamental type of human interaction-one "truly individual and singular"-in the symmetrical immediateness of eye-to-eye contact, whose totality, in a sense, coincides with its flatness.

Among the prominent twentieth century theorists of surfaces, we must also include the zoologist Adolf Portmann. Portmann (1949), p. 35, makes an important claim when he writes that "what is presented to the eye is formed according to different laws from what is invisible." In his view, there exist specific laws of the visible that are distinct from the general law of matter when it is indifferent to the partition between the visible and the invisible. This is why social life comes in the form of a "presentation": if there is perception, it is because something is given to be perceived, something is deliberately presented to the eye. The "seeing eye" is neither a biological organ nor a psychological subject, but a socius, the associated function and presence of the virtual gaze that ties the social animal to relationship. Arguably, it is for this reason that Deleuze and Guattari (1980), p. 345, speak of the imperceptible as a percipiendum-something that must be perceived. Movement, they elaborate, is perceptually relative and structurally imperceptible, because different observers have different capacities to perceive, but all observers can only perceive forms and objects, not metamorphosis, not the movement from one form to another. ${ }^{6}$ However, they add, this only holds with reference to the structural and organizational level of perception. Once a shift is made toward the immanent level (the "plane of nature"), the imperceptible turns into a necessarily perceived: leaving the imperceptibility of movement behind, movement then turns into nothing else than perception itself. What is crucial, it is a new type of perception, the introduction of a new dimension of being, a special transformation of the world as visible world (here again, theory making reveals itself as praxis). The plane of nature is the plane where social life unfolds, like an equation that defines its own "quadratic space", its own vector space.

In sum, the perceptible-or, as we say, the visible-remains distinct from functions, models, and principles; it possesses its own inner laws that are non-codified laws of immanence. While we may be far from laying out these laws exhaustively, this fact already explains the abovementioned irreducibility of the visible to structuralism and system thinking. The visible cannot be resolved into either a field of distributions, or a field of visibility and inter-visibilities; nor can it be deduced as a systemic

appearance, just as the social force is, par excellence, imitation in all its forms, either active or passive, the increasing ardour to proselytise and the overexcited desire to assimilate." (Tarde, 1886): p. 91; my translation.

${ }^{6}$ Notice how Deleuze strategically differs from Merleau-Ponty (1966) on this point: for the latter, in natural contexts, the invisible is the observer, unconscious of its own "complicity with the world." But, how to account then for complex intervisibility stances, such as for instance the one taken by Walter Benjamin, of which his friend Gershom Scholem wrote: "he demands that each person see him, although he hides himself" [quoted in Eiland and Jennings (2014), p. 84]? emergent property deriving from feedback circuits. In fact, the hypothesis followed here is that the ought expressed by the percipiendum (the necessarily perceived, the to-be-perceived) is generated by the very constitution of social life. We do not yet know the proprium of this special type of life. However, what we know is that it is a type of impersonal and anorganic life, distinct from both the biological organism and the sociological organization. What most particularly marks its distinctiveness is the fact of intensity. Social life is not only extensive-positional, relational-but also intensive-significant, "pregnant." Phenomena well known to anthropology, such as the sacred, mana, taboo, charisma, power, value, and pathos, can never be resolved into forms, into pure "saliences"; instead, they need to be accounted for as informal "pregnances." A whole modeling of how saliences and pregnances enter into reciprocal contact, and with which outcomes, has been elaborated by the mathematician Thom (1988) (p. 53-55) in his project for a "physics of meaning." While Thom humbly claims that his "soft schema" is not conductive to any unified vision of the world, his notions of salience and pregnance-understood as, respectively, an individuated form in a substratum space, and a non-localizable propagative force that flows through saliences and impregnates them-prove extremely fruitful in the analysis of the social world. Just as semiophysics presents itself as an archetypal physics, an application of its tenets to social theory may perhaps illuminate the facets of an archetypal social science, yet one capable of dealing with its own mythopoiesis and praxeology.

In this theory, the encounter between two saliences always determines a collision, a struggle between irreconcilable or mutually resistant forms (Figure 1). On the contrary, the effect of a salience on a pregnance can go in either the direction of the salience acting as an obstacle to the propagation of the pregnance, or in the direction of the production of a "pre-programme," whereby, a pregnance can act upon another pregnance thanks to the mediation of a salience now turned into an active transformer and a veritable "archetypal singularity" capable of separating, sorting, and arranging different pregnant flows (among these archetypal morphologies, Thom famously analyzed the water wheel). By contrast, a figurational effect, or, what we call here the production of figurative images, is the outcome of a pregnance investing (impregnating) a salience,

${ }^{7}$ In this respect, it may be instructive to return on a passage from a classic such as Hubert and Mauss' (1902) essay on magic: "A notion that envelops that of magic power has existed everywhere. It is the notion of pure efficacy, which is at the same time a material and localizable substance, but also a spiritual one, capable of acting at a distance and yet by direct connection, if not by contact, mobile and movable without moving, impersonal and assuming personal forms, divisible, and continuous. Our vague ideas of chance and quintessence are but pale survivals of such much richer notion" (my translation). It is also not by chance that the notion of pregnance is extremely close to the natural phenomenon of biological pregnancy. If the German word Prägung has been employed by ethologists to describe the "imprint," the Latin word matrix (from which, mother) was originally employed for the uterus. We have here the extremes for a general analysis of "coinage," which, as the everyday use suggests (e.g., "to coin an expression"), is a highly creative act, and above all an act open towards the production of novelty.

${ }^{8}$ Thom's semiophysics cold be characterized as the analysis of significant forms or, better, the study of the "intelligible ontologies" from which significant forms emerge. 


\section{outcome}

\begin{tabular}{clll}
\hline salience & $<->$ & salience & collision \\
\hline salience & $->$ & pregnance & $\begin{array}{l}\text { obstacle \& } \\
\text { pre-programming }\end{array}$ \\
\hline pregnance & $->$ & salience & $\begin{array}{l}\text { predication \& } \\
\text { figurational effects }\end{array}$ \\
\hline pregnance & $<->$ & pregnance & catastrophic schematism
\end{tabular}

FIGURE 1 | Thom's theory of the interactions between saliences and pregnances via emission, capture, impregnation, and re-emission.

which also evokes an act of predication (Thom believes that the linguistic enunciation is essentially structured as action itself, and more generally that signification is the form of the biological processes that underpin thinking). It is as if the salience now becomes the spokesperson of the pregnance itself, its own aspect (image) being an "effect" of the pregnance's action. Finally, the encounter between two pure pregnances appears as one that is most resistant to formalization, and can only be approximated via a "generalized catastrophe" scheme (catastrophe being a general term for a discontinuity and the disappearance of stable equilibrium from a system); in this latter case, we reach the limits of the notion of form and the nature of the substratum becomes essential (contrary to a purely morphogenetic approach, where the substratum is irrelevant).

The theories of surfaces can be complemented with the analysis of salient/pregnant effects and interactions. Thom's theory is used here to suggest that, instead of conceptualizing the visible as structured around a dichotomy of flatness (the visibility of surfaces) and depth (the invisibility of structures), we may recognize its hyaline nature, which is of an "elemental" nature. In turn, this enables us to think the relations between the visible and the invisible in new terms, acknowledging that, as said above, while something cannot be seen and unseen, there is a constant, complicit coming together of the visible and the invisible. The invisible is the pregnant, the informal correlate that defines the constitution of each form. The notions of image, virtuality, and the infinitesimal may be helpful to articulate the relations between the visible and more familiar social-theoretical notions such as fields and systems.

\section{IMAGES, THE VIRTUAL, AND THE INFINITESIMAL}

The fabric of social life might be more fine-grained than we usually assume. A consideration of the infinitesimal was envisaged in the social theory of Gabriel Tarde and Georg Simmel at the end of the nineteenth century. In particular, Tarde's project for sociology consisted in a science capable of capturing the "infinitely subtle" differences of detail and the "elemental and invisible originalities" (Tarde, 1999b [1898]) that are generated by inter-psychic contacts. For his part, Simmel focused on the myriads of reciprocal actions or "effectuations" (Wechselwirkungen) imparted by the interacting individuals upon each other (Simmel, 1890). Today, these theoretical insights can be revived and expanded by assuming quantum reality. From a theoretical point of view, quantum reality, premised upon the general uncertainty of entangled states (Susskind, 2014, p. 146; $165 ; 251)$, integrally assumes the co-presence of actual and virtual (Penrose and Hameroff, 2014, p. 51-53). The virtual calls for an indeterminacy principle that makes the physical as well as social world look counter-intuitive. ${ }^{9}$ So, the visible is "only" virtual, but each actual occasion, each individual object is surrounded by a cloud of virtualities from which it emerges and into which it baths, at times barely distinguishable. Now, that a (physical or social) situation can be simultaneously in different states derives from virtuality being in relation to on-going imaginational production: as recalled above, each actual (social) fact is surrounded by a mist of images ${ }^{10}$-or, to paraphrase Bergson, materials naturally prolong into images.

The hypothesis advanced here is that the virtuality of images is of the same type as the virtuality of the social. In short, images can be found at the root of social life. Images are natural productions, in the sense that nature constantly produces images: nature is "imageal". Perhaps, this is why the study of images

\footnotetext{
${ }^{9}$ Adolphe Quételet, one of the great early nineteenth century statisticians, forged the notion of "social physics" in 1835. At the end of the nineteenth century, the idea that sociology could be grounded in a physicalist paradigm was rejected by both Durkheim and Tarde (despite both used several mechanical metaphors in their writings). Today, aware as we need to be against reductionism, it may still be interesting to explore the connection between physics and sociology. As concerns the difference between classical and quantum physics, see the succinct explanation by Susskind (2014), p. 251: "Things that would be simultaneously knowable in classical physics may not be in quantum mechanics. Different components of a spin are an example. One cannot know both components simultaneously; therefore, one does not have states in which both components are specified."

${ }^{10}$ Images are not necessarily only visual; it is easy to conceive for instance of acoustic images, olfactory images, tactile images, and so on. Of course, different senses and different synesthesic affects might possess different degrees of imageability-their mist might be thicker or lighter.
} 
has always tended to elicit a more or less explicitly vitalisticanimistic approach. The iconologist and image theorist Mitchell (1996) for instance has suggested that images may be endowed with volition. Following his invitation, it becomes possible-and interesting-to study, not so much the power of images, but their desire. ${ }^{11}$ A relational foundation is thus placed at the root of images that contradicts the solipsistic isolationism of Cartesian philosophy. More pointedly, it contradicts to representationalism as a theory of images. In this vein, for the French philosopher Simondon (2008 [1965-1966]), it is thanks to images that psychic life contains a social dimension. A leading motif in psycho-social individuation is enacted by the life of images. In fact, imagines do not exist as single, separated entities, rather, they come in groups, they form populations, colonies endowed with rich interactive textures. With images, it is never a matter of a simple figure/background binary. Images are not objects, but couplings between the actual objectivity and the virtual imageability; they resemble what Von Uexküll used to call the Umwelt, the "world nearby" - it is nearby not because of physical distance, but because of the aimed, intended opening between the individual and the environment. Which model of image can support these claims? Simondon advances two intriguing metaimages (images of images): on the one hand, he says, images are like a "foreign population inside a well-organized state"; on the other hand, they are like "organisms inside the living organism." A double reading is proposed: on the one side, an ethnic minority inside a nation (let's call it a "political" image of images), on the other, parasites or viruses inside a host organism (a "biological" image of images).

The peculiar ambivalence of images lies in the fact that they swing between an existence as rare, endangered species, and an existence as unruly, disobedient creatures reproducing like rabbits or lemmings. Contrary to concepts, Simondon notices, images can only be governed indirectly. If images are parasites, it is interesting to recall the definition of parasite given by Serres (1980): the parasite is a "relational atom."12 Certainly, we expect an atom to be a "thing," as opposed to a relation lacking any specific substance. What the paradoxical expression refers to is that the parasitical relation predates exchange or, as Serres puts it, one-way arrows precede two-way arrows. Parasitism is a type of relation, but a sternly non-reciprocal one, drifting toward unlimited, cascading chains. Parasites, from this perspective, are stand-alone (atoms) and yet simultaneously deeply relational beings. The parasite is a creature that lives inside an (ecological) system and does not cease to sabotage the system's creation of a central-gravitational identity (a "we-ness"). The parasite is an unrepentant free-rider who defuses totality. All systems are

\footnotetext{
11 "Images are certainly not powerless, but they may be a lot weaker than we think. The problem is to refine and complicate our estimate of their power and the way it works. That is why I shift the question from what pictures do to what they want, from power to desire, from the model of the dominant power to be opposed, to the model of the subaltern to be interrogated or (better) to be invited to speak. If the power of images is like the power of the weak, that may be why their desire is correspondingly strong, to make up for their actual impotence." (Mitchell, 1996), p. 74. 12 "The parasite is an element of relation, it is the atom of relation, the Sagittal atom, the arrow element, the arrow flying at random in the clarity of daylight. The apparition of sense." (Serres, 1980), p. 332; my translation.
}

unmistakably affected by parasites, these thoroughly a-moral creatures who operate the interruption of flows and the extraction of assets. Since the parasite is an interrupter, and parasites also parasitize each other, only one host-guest line can become actual, whereas the others-the dotted ones-remain virtual, as represented in Figure 2.

Even if we tend to dislike images in their capacity as parasites (really, who sympathizes with parasites?), we may re-appreciate them as ethnic minorities. Here lies the ethical component of images. Why can images be likened to an oppressed, heavily policed, prosecuted minority? What does it mean to say that images may actually be political prisoners? The fact is that images are irreducible to the "state power" held by structures and organizations. Images are not law-abiding, average citizens; on the contrary, they always look unstable, suspect. Even if it may sound a strong claim to contend that images are "without a face," to observe them as illegal migrants, as refugees who often lack official or at least credible documents, carries a strong heuristic potential. The very impulse to gloss, comment, tag, and index images testifies a contrario how images appear but do not possess a face. Images are the sans-papiers and sans-abri of the visible; they constantly position us, who watch them and use them and are affected by them, in the ethical position of responsibility - the Levinasian responsibility of facing irreducible diversity.

As both parasites and minorities, images appear to be inherently connected to movement. In a basic sense, images correspond to the animal's capacity to project itself beyond its own proper body. Imaginative production thus embodies an extension of the self. Similarly, for instance, Bergson (1912) remarked that, thanks to sight, we beam beyond ourselves-nous rayonnons au-delà de nous. By allowing us to turn into "rays," images do contain a promise of mobility and delocalization. ${ }^{13}$ Notably, the movement of images is not Newtonian, but quantic: it is movement as inherently transformative of events, rather than simply translational of objects. An important consideration is that images possess not only an outer mobility but also an inner one that corresponds to their metamorphic state. Because of inner mobility, the relation between image and meaning remains unsettled, open: images

${ }^{13}$ The opposite movement should also be considered, whereby we let ourselves be "invaded" by the environment. Possibly, plants - as well as more generally all forms of life, including the non-organic (water, fire, meaning...)-also know a similar two-way imaginative and imaginational production; unfortunately, this topic cannot just be meaningfully tackled here.

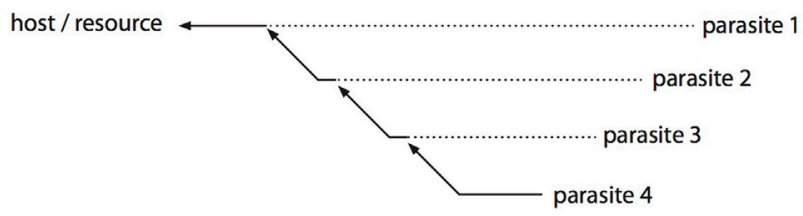

FIGURE 2 | Parasites as "relational atoms," images as parasites-Note the difference between continuous (actual) and dotted (virtual) lines, as well as the dominance of one-way arrows. 
are intimately tied to the creation and growth of meaning. ${ }^{14} \mathrm{~A}$ similar openness also exists vis-à-vis definition and identity. The "elemental" nature of images is tied to their being "impersonal, preindividual, acosmic" entities (Deleuze, 1969) p. 208. Deleuze (1981 [1970]), p. 67, also highlights how, for Spinoza, affections are always intimately associated with images. Indeed, images are "images-affections", in the sense that an affection is the imageal composition of the constitutive relations of a body or mind as it enters into different encounters. Images introduce us to the peculiar condition of that "immortal society" first evoked by Durkheim and so finely excavated by Garfinkel (2002). ${ }^{15}$ To effectively inquiry into the visible as an imageable medium, we need to account for not simply the existence of images, but also the varying degrees of individuation with which images come and their ensuing figurational effects. The Durkheimian dictum so cherished by Bourdieu, "social things are not what they are," can be appreciated precisely from the perspective of an individuation that occurs in various degrees (or, in phases), so that each thing is never exhausted in its present attire, but retains further degrees of individuality to be excavated and actualized in the course of social life. If we accept that, from one image to another, a sort of metamorphosis occurs ("catastrophe") and that, simultaneously, the same image may reappear in disparate places thanks to a sort of teleplasty, then we begin to attain the reality of images as meta-local entities, and can consequently raise the question concerning the degree of individuality possessed by each single image. Social theory must gain confidence with the existence of faceless image-populations that breed moments and forms of individuation, occurring in degrees.

Images exist as living populations, they move around in crowds-as crowds. Certainly, social theory has acquired that a collective-such as a population-is not a mere summative aggregate of individuals. However, if not a sum, what else is it? No general agreement is reached upon this latter point. Social multiplicities are still "ambiguous multiplicities," suspended between holism and individualism (Brighenti, 2014). Perhaps, it is suggested here, the quandary of social theory may be dug into more deeply by considering the notion of proximity or neighbourliness. ${ }^{16}$ The objet and its images, or, images and their objects, exist in a state of mutual proximity. It is an infinitesimal proximity, which proves to be of meta-local nature. What in physics Einstein once contemptuously dismissed as spukhafte Fernaktion (spooky action at distance) might be quite pointedly what social life really entails. ${ }^{17}$ In this sense, it is true of both images and populations

\footnotetext{
${ }^{14}$ At bottom, it is clear that all theories are images- "ways of seeing," "ways of visualising." This is why, as we theorize images, we are caught in a looping and entangled state. On the other hand, the first theory ever produced by nature were the eyes, these first theoretical organs.

15 "Immortal is a metaphor for the great recurrencies of ordinary society, staffed, provided for, produced, observed, and observable, locally, and mutually accountable in and as of an 'assemblage of haecceitates"' (Garfinkel, 2002), p. 92.

${ }^{16}$ In his later text on the virtual, Deleuze (1996) employs precisely the term voisinage. ${ }^{17}$ Known as the Einstein-Podolsky-Rosen paradox. The problem resides in the fact that, in entangled states, one particle is sensitive to the measurement performed on the other particles belonging in the same state even though no information can be passed between them. The phenomenon is also known as quantum nonlocality and violates the assumption that separated measurement processes are
}

that they are "already number, still unit." ${ }^{18}$ One wonders about the force that can keep together the constitutive elements of a multiplicity even at a distance or, which is the same, in a situation of non-metric proximity. Usually, we trust the fact that the individual provides for a clear unit in the composition of social life. But, at the limit of the individual-and the individual is so constituted that it has vast liminal regions-we find nothing but crowds (Brighenti, 2010b). If crowds are close to the kernel of social life, it is because crowd states are like eigenstates, they entail a shift to the infinitesimal: they constitute the limits of all individual objects, past which the individual dissolves, disappearing into the environment. ${ }^{19}$ The individual then is like a minimal element, a threshold of consistence, a local convergence of qualities and properties, a set of temporarily appropriated qualities-an haecceitas. ${ }^{20}$ Yet, such minimal creature of coalescence is constantly exposed and traversed by singularities that are anisotropic moments, exceptions, or occasions. Caillois (1935), for instance, analyzed animal camouflage as a quest for invisibility entailing a corresponding loss of individuality. Well beyond the animal domain, Caillois speculated, invisibility persists as a "permanent longing" in humans entailing an essential apprenticeship in visibility management. Images sit and play on the beach at the margins of the visible, half-washed by the sea of the visible: always in a thriving status, they host crowds.

Why is it useful for today's social theory immersing into a careful scrutiny of notions such as the image, the virtual, and the infinitesimal? The answer can only come from a development of the analysis of the visible as the "element" of social life. Here, it is only possible to roughly sketch out how such elemental analysis might look like, in view of further elaborations.

\section{PROLEGOMENA TO ELEMENTAL ANALYSIS}

The analysis of the element differs significantly from the analysis of forms and substances, from groups and individuals, as well as from actors and networks. Consider the ambivalence of the notion: certainly, the element is a component, an item that becomes part of an ensemble-so, one can be an element of a group or of a set. However, especially if we understand it through Aristotelian physics, the element manifests itself as the "stuff" in which the

independent processes: indeed, here measurement results on unrelated, distant and non-interacting subsystems appear to be correlated. Incidentally, it is impossible not to be reminded of the second law of magic fleshed out by Frazer (1994 [1890]), known as the Law of Contact.

${ }_{18}$ "Of each multiplicity we must say: it is already number, it is still unity" (Deleuze and Guattari, 1980: 605; my translation).

${ }^{19}$ Let us briefly mention that this may be one of the reasons why both Tarde and Simmel were extremely interested in crowds. Sociology was born in the cradle of the late nineteenth century debate on crowds (Borch, 2012).

${ }^{20}$ In this vein, Canguilhem (2015 [1951]), p. 89; my translation, defined the individual as a "liminal" and "minimal" being: "The individual is a being at the limit of non-being, since it is what cannot be fragmented further without losing its proper characters. It is a minimum of being. But no being is a minimum in itself. The individual necessarily presupposes in itself its own relation to a larger being; it calls for, it requires ... a background of continuity upon which its discontinuity detaches itself." Note that what Canguilhem here calls "discontinuity" resonates neatly with Thom's notion of salience. 
items are placed. As known, Aristotle identifies five essences, seeds or elements: four terrestrial-water, air, earth, fire-and one celestial, the aether. Using the notion of element (which may be likened to the notion of substrate in Thom's semiophysics) to tackle the nature of social life draws attention to the finest qualities of the materials entailed in social dynamics. The social equation has indeed its specific materials and its specific ways of orchestrating them. These materials are neither substantial nor formal. It is the late Merleau-Ponty (1966) who, researching into the notion of the visible, crafted a modern idea of element, which he called the "flesh of the world." He understood it as an alternative to both substantialism and formalism. ${ }^{21}$ His insight is precious for social theory, given that the social is as unsubstantial as it is informal. In this respect, Merleau-Ponty employs two quite remarkable expressions, namely "general thing" and "incarnated principle." At first, both expressions seem to fall prey of a contradictio in adjectum. On the one hand, a thing or object is supposed to be specific, so that a general object is not quite an object, or no longer one; on the other hand, a principle is supposed to lie beyond specificity, so that anything "incarnated" cannot be said to be a principle, or not yet one. Yet, once we think through these locutions, we begin to realize how precisely the element is always located "in between" the general and the specific. Such inbetweenness Merleau-Ponty captures in terms of an adherence between the visible world and the seeing body. As a totality, he remarks, the visible always lies beyond, after, or in between the aspects of it which we see. The visible thus embodies a mid-terrain, a domain of, simultaneously, facticity - the origin of all possible factuality-and semioticity - the origin of all meaningfulness. On this basis, it is even possible to argue that Merleau-Ponty is the first to overcome phenomenology: his notions of "anonymous visibility" and "generalized vision" can no longer be explained within a phenomenological framework. The tags "anonymous" and "general" appended to the visible are fundamental qualifications of social life for, as we have seen, subjectivity (either individual or collective) is a late addition to the social—or, to put it in a different light, one of its special attainments. ${ }^{22}$

An "elemental-analytical" approach is intended as an enlargement and overcoming of structural-systemic theories. The notions of system, structure, field, and network are diagrammatic and logistic. They tell us that individual objects must be appreciated in

${ }_{21}$ "The flesh is not matter, it is not spirit, it is not substance. To designate it, one might need the old term of 'element,' in the sense in which it was used to speak about water, air, earth, and fire. Such is the nature of a general thing, halfway between the spatiotemporal individual and the idea, kind of incarnated principle that bring a style of being everywhere a parcel of it can be found. The flesh is in this sense an 'element' of Being." (Merleau-Ponty, 1966), p. 181-182; my translation.

${ }^{22} \mathrm{An}$ important corollary and conclusion that can be retained from Merleau-Ponty: it is a relationship of the visible with itself that constitutes the viewer. Compare this insight with Deleuze and Guattari's idea that the percipiendum forms an anonymous percept. On this point, it may also be fruitful to refer to Janet (2005 [1929]), who argues that the primal psychic work is objectivation. Similarly, for Simmel (2011 [1900]), p. 67, "the awareness of being a subject is already an objectification". Accordingly, the genetic sequence would be as follows: 1. object; 2. environment; 3. subject. It is the object that creates the space for a subject, yet, it is only thanks to the environment and the individual-environment relation that a subject can come to exist. Also, the subject is never alone, for-as argued by Janet-all practices of subjectivation are inherently practices of inter-subjectivity. terms of their reciprocal positions, of their oppositions, their normalized (scaled) differences, and more generally of their relations. This is certainly important. However, a simply logistic interpretation of the visible would fail to account for the existence of heating, intensive points in the visible and of the visible itself. This is why the visible cannot be a substance. The substantialist perspective fails to grasp its processual, transformational, and metamorphic nature. The visible can be better imagined as the domain where individuations and-correspondingly-environmentalisations take place. In other words, the visible is the element-the zone or medium-in which reality comes to be doubled into image and background, object and environment, fact and potency, actual and virtual energy. ${ }^{23}$ The visible is the element where the couple object/environment can appear. There is no proper environment that precedes the object, for the two come into existence at once. One of the subtlest insights we inherit from Simondon is the idea that, just as the individual derives from a process of individuation, so too does the environment. In other words, the environment is a correlative production to the production of the individual-individual-environment forming an unbreakable couple, an Umwelt. A fortiori, this means that we cannot join an environment without also concurrently transforming it. In this framework, the visible is not, properly speaking, to be counted as an environment. Rather, it is the possibility and the reservoir for environments and objects to come, taken as they are in reciprocal relations and a co-definition.

The element is pregnant. Elements are, to gloss again MerleauPonty, "styles of being" that are actualized by mobile, singular particles functioning as heralds of a certain style. For the social theorist, understanding and measuring the exact nature of such particles of the visible may be no less important than it is for physicists to apprehend the nature of subatomic particles. At present, it is hard to establish whether or not we are actually dealing with the same types of particles (wave-particles) and whether, consequently, the chimera of social physics can be revived: either way, what seems essential is the passage to the infinitesimal, to the quantic. From this perspective, objects can be described as emergences and coalescences in the visible. Visibility is thus a relationship, which only makes sense inside an element that articulates objects and their environments. As we have seen, between object and environment, there cannot be any precedence. The distinction is not ontological; instead, it is a difference between two ways of inscription into the visible. It is, as Merleau-Ponty first saw, a matter of styles of being. While visibility can be attributed to

\footnotetext{
${ }^{23}$ The theory of the visible as medium proposed here cannot be thoroughly reconciled with the Gestalt theory of objects and media elaborated by the Austrian psychologist Fritz Heider. In an early crucial essay from 1922, titled Ding und Medium, Heider (1959) argued that that "mediators" (the media) and "mediated objects" differ by nature. Objects are hard, cohesive entities made of parts that are mutually dependent in a strict sense, whereas mediators are soft, unarticulated, and neutral. Contrary to what argued by Heider, the distinction between cohesive and uncohesive materials is not a distinction between different types of objects, or between different types of media, or even between different types of events (such as what Heider terms "thing events" vs "wave events"), but rather a struggle that is intrinsic to every object/environment threshold. The neglected dimension in classical Gestalt theory-as well as in several contemporary theories of the visual and visuality—is a thinking of forces, rather than "simply" forms.
} 
certain objects within the environment, the element as medium, coincides with the visible, integrally understood. The visible is not a container, but a threshold of inscription, whose limits and margins are always in a thriving status: the visible exists in a state of virtual crowd. If objects emerge, it means they only exist within a given range; for the rest, there lies the vast expanse of crowds (populations).

Instead of a structuralist, systemic or symbolic interpretation of the visible, the notion of element supports and invites a study of the fiber. Anything but a homogeneous medium, the visible possesses a unique fiber. Here, it is possible to see how hard and soft materials, "things" and "media" are cut in the same stuff. The modulations of the fabric of the visible can only be reconstructed starting from the domain of the infinitesimal. Two basic conditions seem to apply:

- $(n+1)$ principle of increasing complexity: what is at each time added $(+1)$ is not a layer of substance, but a perspective, a cut through the world, a living point of view (the invisible adds to the visible, instead of being subordinated to it);

- $(n-1)$ principle of constitutional incompleteness: the Element is anything but unit, it is everything except one. What is subtracted $(-1)$ is the completeness of individuality, insofar as the element is constitutively non-individual.

Functioning as the obverse of a multiplicity, the visible is something about which we should say that it is "no longer unit, not yet number." The specific nature of the element thus entails a significant reversal of the coordinates laid out by Deleuze and Guattari in their analysis of multiplicities. In the following, a set of entangled notions are presented that may serve as an approximation of the fiber of the visible. Jointly, they help explain how the visible constitutes the social at the same moment when the social gets inscribed into the visible. What makes social life so complex, it is suggested, is not its immateriality (after all, immateriality is actually... "incompetent, irrelevant, and immaterial"), but its invisibility substantiating its very visibility. The notions presented below can be considered in couples distributed along an entangled circuit represented by the complex operator " $\boldsymbol{V}$." This operator denies both identity and opposition, but leaves scope for a subtle collaboration between the linked terms. ${ }^{24}$ As illustrated in Figure 3, there are two "large circuits," namely:

- element $\backsim$ Element

- milieu $\backsim$ environment

and two "small circuits," that is:

- object $\sim$ image

- individual $\mathrm{c}$ element

On the left side of Figure 3, a synoptic view is offered, on the right side, a processual view. The irreducible ("irrational") relation between the numbers 2 and 3, tied in a W-shaped dynamic, specifies the nature of the two circuits and prevents the visible from falling prey of either binaries or trinities. The circuits are enacted by the circulation of pregnances in social life.

Let us examine the two large circuits. First, the "element os Element" circuit spans an "element" understood as individual item-or, what "adds up to" a certain composition-and the "Element" understood as medium-or, what "never boils down to" a given collection of items. Whereas the element is the individual, or atom, the Element is the connective texture, or relation; it encompasses and infiltrates. The Element predates the milieu/environment, being precisely what makes the constitution of all milieus possible. In his sociological monadology,

\footnotetext{
${ }^{24}$ The quantitative determination of this operator remain open for future investigations. What is offered here is not a science of the visible, only its Fragestellung and prolegomena.
}

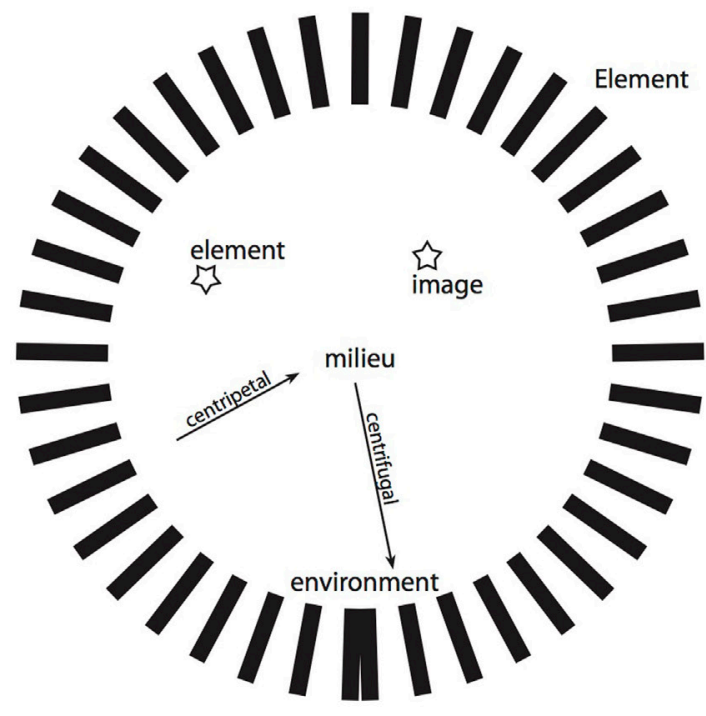

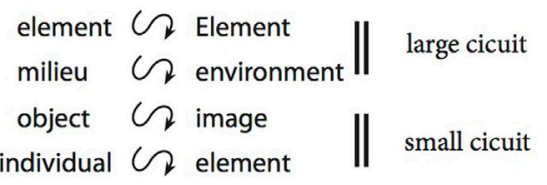

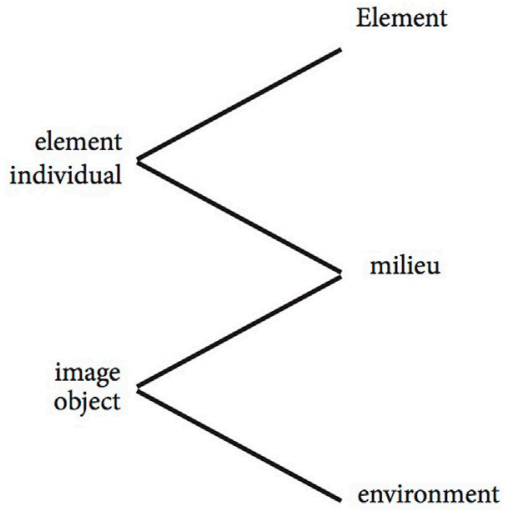

FIGURE 3 | The fibre of the visible. 
Tarde (1999a [1893]) first theorized that the discontinuity of elements is always coupled with the continuity of the milieu. In his theory, the element features as the infinitely small, the infinitesimal-something that differs from the finite by nature, and not simply by degree. Similarly, for Thom, a theory of discontinuities (catastrophes) is embedded in a continuist substrate. Everything in social life descends from the infinitesimal and returns to it: the element is the smallest conceivable individual, a non-localizable individual. The infinitesimal is also the domain of the invisible, the space of the non-formal. Conversely, we may call visibilisation any technique aimed at individualizing the element, that is, aimed at producing or obtaining an individual from an environmental milieu. It is thus in the medium of the visible and in the field of visibility that it is possible to constitute something as an individual thing or a formed object. In Thom's conceptualization, every birth can be said to be a visibilisation, every death an invisibilisation.

Second, then, we can consider the "milieu $\sim 2$ environment" circuit. In a rounded space, or curved space-time, characterized by intensive magnitudes ("pregnances"), the milieu and the environment designate the same phenomenon observed from different and, so to speak, complementary points of view. In fact, the milieu is the effect of a centripetal (implosive) vector-an "absolute speed of (invisible) movement"-the environment of a centrifugal (explosive) one: whereas the milieu is meaningful, the environment is expressive. The milieu is the absolutely local that comes into dialog with the environment as embodying the relatively global. The "milieu $\backsim$ environment" circuit thus emphasizes the fact that the medium, understood as element, is metastable. Whenever the medium becomes over-saturated or over-impregnated, it goes beyond stability and may "precipitate" at any moment. Here is how forms coalesce in it. The visible is filled with structural germs, intensive invisible items endowed with a high potential of propagation and metamorphosis. Such germs of forms are only effective under conditions where the medium is already "more than ready" for change. ${ }^{25}$ Formations thus appear through coalescence. The process is simultaneously one of mise-en-forme and prise-de-forme. It follows that every hierarchy in the visible occurs as stabilization of the original phenomenon of intensity or "pregnance." Social order, we may say, is the visible outcome of such stabilization process.

The two large circuits set the scene for the two small circuits. The latter take place in a proximal, indiscernible space; it is a nondescript space with which a theory of the visible must begin to familiarize. In fact, just as the "object $\sim$ image" circuit breeds unbreakable object-images, the "individual $\sim 2$ element" circuit breeds individual-elements. Object-images speak of the open-ended affectivity of engagement with active materials, while simultaneously individual-elements speak of a principle of individuation that is dynamic and unfinished (in fact, a process more than a principle). "Bodies ... combine with and affect one another, each one leaving 'images' in the other, the corresponding ideas being imaginations"; "images are the corporeal affections

\footnotetext{
${ }^{25}$ See the elaboration by Simondon (2005 [1964-1989]) on individuation as an inherently processual, stratified, and phased phenomenon.
}

themselves (affectio), the traces of an external body on our body" Deleuze (1981 [1970]) p. 101. The individual gives a name to the element by producing individual-elements, so that the imagist production may populate the visible with sensitive entities or objects. In the terms introduced above, the individual-element is a figurative effect of (a predication that derives from) the advent of a pregnance onto a salience. Social life is an imageal production. Once again, it is matter of distinguishing between medium and multiplicity, for the object (or entity) is, in fact, one such multiplicity, split as it is between one actuality and its accompanying almost-indiscernible virtualities. As seen above, the visible constitutes the medium or Element where the couple object/ environment can be recorded, so that no proper environment exists before the object, the two coming into existence at once. The installation of objects and environments is genealogically followed by the inception of subjectivity, which in turn is always inter-subjectivity-it is already relation. From this perspective, the subject is a late comer to social life who finds itself "operated by" (sub-jectum, thrown below) the object/environment dynamism and can only appear in the form of an inter-subjective network. The standard social science notions of "social interaction" and "social structure" both result from what Thom (1988) (p. 67) defines topologically as the "coincidence of the co-folds" in a double-hysteresis cycle: the sense of purposefulness in the social, sive subjectivity (individualistically or collectively conceived), arises precisely from such topological strategy of coincidence operated in a space where saliences and pregnances are brought together.

Taken for itself, the visible is neither objective nor subjective. Certainly, visibility - understood as a quality and a resource - can be appropriated by subjects as well as predicated of objects. But, the visible can never be privatized: it is an anonymous visibility that appears in "animistic moments" (Kärrholm, 2016) (p. 75). Moments of animation pervade the visible, distributing agency and subjectivity in singular points that may eventually be occupied by individuals in relations. As Kärrholm describes it, the outcome of animistic moments is "the becoming of a living and moving body, a figuration, which also figurates my body or other associated bodies." Such exceptional qualitative moments might perhaps also be called, rephrasing Whitehead, "uncoordinated actual occasions." They are uncoordinated, and yet it is within this texture that phenomena of coordination may be undertaken.

\section{TRAJECTORIES OF THE VISIBLE, TRAJECTORIES IN THE VISIBLE}

The argument advanced so far is that the visible cannot be reduced to either structure, system, field, network, or other similar social theoretical notions. Instead, it is suggested that it could be fruitfully conceived of as the original element in which the items of a structure, the parts of a system, the positions of a field, and the diagrams of a network can be established. A dynamic appreciation of the visible enables us to understand the acts of inscription into it as a form of "natural writing." Such writing in the visible comes through not only inscription, but also stratification, scratching, projection, vibration, impregnation, fossilization, 
piercing, fraction etc.- - all operations that consolidate, modulate, or modify the degree of consistence of a fiber. Many different "flections" are possible in the visible that are also flections of the visible itself. Such flections operate as folds of the specifically local onto the generally global, or, as a conjuncture of absolute and relative that affects the state of the medium. What above has been referred to as the fiber of the visible corresponds to the functioning and outcome of such flections. It is through a series of operative ways, or ways of operating in the visible, that similar flections are produced. Magic and technology (particularly as described by Mauss) offer in this sense two exquisite examples of similar operative ways, although certainly several other ways could be envisaged.

To the extent that a theory of the visible takes into account the natural writing of the visible, it also necessarily includes a trajectology, that is, a whole study of trajectories in topological spaces. The latter is articulated at (at least) two levels: (a) the analysis of trajectories in the visible; (b) the analysis of trajectories of the visible. Ad (a), the trajectories that inhere in the element of the visible are of relevance. These trajectories determine a veritable logistics of the visible. Adverbs and prefixes such as "para-" (by), "meta-" (beyond), "infra-" (beneath) modulate the ways in which objects and events are written in the visible. The parasite is nearby the grain, the element is beyond equilibrium, images slip beneath the threshold of form. The acts of inscription into and projection onto the visible may also be articulated in terms of meta-inscription and infra-projection, with respect to the specific functionality and connections between the engaged materials. Relations - which we ultimately call social relations-are constituted on the basis of these trajectories and the relative encounters they generate. Encounters are never anodyne, but constitutive of object/environments stabilizations. Ad (b), it is then necessary to recognize that the visible supports not simply a logistic set of distribution, but also and especially an intensive zone of encounter. An "intensiology," understood as a science of social intensities, is thus a fundamental requirement to account for the metamorphic threshold states of the medium. For thresholds are always zones of hesitation, undecidability, coming formation.

At this point, we are far from having fully articulated the immanent laws of the visible. The aim of this paper has simply been to suggest that, in order to advance toward a comprehension

\section{REFERENCES}

Bennett, J. (2009). Vibrant Matter: A Political Ecology of Things. Durham: Duke University Press.

Bergson, H. (1912). "Lâme et le corps," in Lénergie spirituelle, ed. H. Bergson (Paris: Alcan), 1919.

Borch, C. (2012). The Politics of Crowds: An Alternative History of Sociology. Cambridge: Cambridge University Press.

Brighenti, A. M. (2007). Visibility: a category for the social sciences. Curr. Sociol. 55, 323-342. doi:10.1177/0011392107076079

Brighenti, A. M. (2008). Visual, visible, ethnographic. Etnografia e Ricerca Qualitativa 1, 91-113. doi:10.3240/26001

Brighenti, A. M. (2010a). Visibility in Social Theory and Social Research. Basingstoke: Palgrave Macmillan.

Brighenti, A. M. (2010b). Tarde, Canetti, and Deleuze on crowds and packs. J. Class. Sociol. 10, 291-314. doi:10.1177/1468795X10379675 of these laws, and consequently in order to appreciate the magnitudes of the social medium, we must first account for a series of aspects, including the "in-betweenness" of the visible (already remarked by Merleau-Ponty) and its threshold states (assumed through quantum reality). These in turn can only be ascertained through a theoretical passage to the regime of the infinitesimal-that is, the zone where all social formations come from. Recognizing the intimate collaboration (complicity, or again coincidence of co-folds) of visible and invisible, of actual and virtual, of factual and imageist, encourages us to advance toward a sort of neo-vitalist exploration that takes seriously the notion of life of the social. Perhaps, in respect of this, the truest insight of vitalism-one that survives its many shortcomings and its many rejections-lies in regarding life not as an individual phenomenon, but as an elemental one. The ought of the visible, or, what we have called the percipiendum (which at this point we may also recognize as the ought of theory, its praxis) can only be understood with reference to the elemental nature of social life, as defined by its actual-virtual circuits tentatively sketched above. A renewal of vitalism may be already under way in various fields ${ }^{26}$; it is not excluded that a renewed vitalism may also prove beneficial for a global reconstruction of social theory in the twenty-first century.

\section{AUTHOR CONTRIBUTIONS}

The author confirms being the sole contributor of this work and approved it for publication.

\section{ACKNOWLEDGMENTS}

I wish to thank John Levi Martin for reading and discussing an earlier version of this paper, and especially for pointing my attention toward Fritz Heider's work. I also wish to thank the editor Maurizio Meloni and two anonymous reviewers for their encouraging comments and request to improve this text. Limitations are my own.

${ }^{26}$ Suffice here to recall the recent scholarship of Bennett (2009) in philosophy, Ingold (2011) in anthropology, and Kärrholm (2016) in architecture.
Brighenti, A. M. (2014). The Ambiguous Multiplicities: Materials, Episteme and Politics of Some Cluttered Social Formations. Basingstoke: Palgrave Macmillan.

Caillois, R. (1935). Mimétisme et psychasthénie légendaire. Minotaure 7, 5-10. Canguilhem, G. (2015 [1951]). La connaissance de la vie. Paris: Vrin.

Debray, R. (1991). Cours de médiologie générale. Paris: Gallimard.

Deleuze, G. (1969). Logique du sens. Paris: Minuit.

Deleuze, G. (1996). "L'actuel et le virtuel," in G. Deleuze and C. Parnet, ed. Dialogues (Paris: Flammarion), 2008.

Deleuze, G. (1981 [1970]). Spinoza. Philosophie pratique. Paris: Minuit.

Deleuze, G., and Foucault, M. (1972). "Les intellectuels et le pouvoir," in G. Deleuze, ed. L'Île déserte et autre textes (Paris: Minuit), 2002.

Deleuze, G., and Guattari, F. (1980). Mille Plateaux. Paris: Minuit.

Eiland, H., and Jennings, M. W. (2014). Walter Benjamin. A Critical Life. Cambridge, MA: Harvard University Press.

Frazer, J. G. (1994 [1890]). The Golden Bough. Oxford: Oxford University Press. 
Garfinkel, H. (2002). Ethnomethodology's Program. Working Out Durkheim's Aphorism. Lanham: Rowman and Littlefield Publishers.

Heider, F. (1959). On Perception, Event Structure, and Psychological Environment. New York: International Universities Press.

Hubert, H., and Mauss, M. (1902). "Esquisse d'une théorie générale de la magie," in Sociologie et anthropologie. ed. M. Mauss (Paris: Puf), 1950.

Ingold, T. (2011). Being Alive. London: Routledge.

Janet, P. (2005 [1929]). Lévolution psychologique de la personnalité. Paris: L'Harmattan.

Kärrholm, M. (2016). The animistic moment: Clarice Lispector, Louis Kahn and the Reassembling of Materialities. lo Squaderno 39, 71-77. Available at: http:// www.losquaderno.professionaldreamers.net/wp-content/uploads/2016/03/ losquaderno39.pdf\#page $=71$

Luhmann, N. (2012). Introduction to Systems Theory. Cambridge: Polity.

Magritte, R. (1966). Lettre à Michel Foucault. Available at: http://www.deslettres.fr/ lettre-de-rene-magritte-a-michel-foucault/

Martin,J. L. (2003). What isfield theory? Am.J. Sociol. 109, 1-49. doi:10.1086/375201

McLuhan, M. (1994 [1964]). Understanding Media: The Extensions of Man. Cambridge, MA: MIT Press.

Merleau-Ponty, M. (1966). Le visible et l'invisible. Paris: Gallimard.

Mitchell, W. J. T. (1996). What do pictures 'really' want? October 77, 71-82. doi: $10.2307 / 778960$

Penrose, R., and Hameroff, S. (2014). Consciousness in the universe. A review of the 'OrchOR' theory. Phys. Life Rev. 11, 39-78. doi:10.1016/j.plrev.2013. 08.002

Portmann, A. (1949). Animal Forms and Patterns: A Study of Appearance in Animals. London: Faber and Faber.
Serres, M. (1980). Le parasite. Paris: Grasset.

Simmel, G. (1890). Über soziale Differenzierung. Soziologische und psychologische Untersuchungen. Leipzig: Duncker \& Humblot.

Simmel, G. (1908). Soziologie. Untersuchungen über die Formen der Vergesellschaftung. Berlin: Duncker \& Humblot.

Simondon, G. (2005 [1964-1989]). L'individuation à la lumière des notions de formes et d'information. Paris: Jérôme Millon.

Simmel, G. (2011 [1900]). The Philosophy of Money. New York: Routledge.

Simondon, G. (2008 [1965-1966]). Imagination et invention. Chatou: Éditions de la transparence.

Susskind, L. (2014). Quantum Mechanics. London: Penguin.

Tarde, G. (1886). La criminalité comparée. Paris: Alcan.

Tarde, G. (1999a [1893]). Monadologie et sociologie. Paris: Synthélabo.

Tarde, G. (1999b [1898]). Les lois sociales. Paris: Synthélabo.

Thom, R. (1988). Esquisse d'une sémiophysique. Paris: InterEditions.

Woodiwiss, A. (2005). The Visual in Social Theory. London: Continuum.

Conflict of Interest Statement: The author declares that the research was conducted in the absence of any commercial or financial relationships that could be construed as a potential conflict of interest.

Copyright (c) 2017 Brighenti. This is an open-access article distributed under the terms of the Creative Commons Attribution License (CC BY). The use, distribution or reproduction in other forums is permitted, provided the original author(s) or licensor are credited and that the original publication in this journal is cited, in accordance with accepted academic practice. No use, distribution or reproduction is permitted which does not comply with these terms. 